\title{
Effects of Sodium Diclofenac on the Distribution of Fos Protein in Central Amygdala and Lateral Hypothalamus during Experimental Tooth Movement in Rats
}

\author{
Ana Paula R. Novaes', Amanda C. Desiderá2 , Glauce C. Nascimento1, \\ Christie R. A. Leite-Panissi ${ }^{1,2^{*}}$ \\ ${ }^{1}$ Psychobiology Graduate Program, School of Philosophy, Science and Literature of Ribeirao Preto, University \\ of Sao Paulo, Ribeirao Preto, Brazil \\ ${ }^{2}$ Department of Morphology, Physiology and Basic Pathology, Ribeirao Preto Dentistry School, University of \\ Sao Paulo, Ribeirao Preto, Brazil \\ Email: ${ }^{*}$ christie@forp.usp.br
}

Received 17 April 2014; revised 10 May 2014; accepted 17 May 2014

Copyright (C) 2014 by authors and Scientific Research Publishing Inc. This work is licensed under the Creative Commons Attribution International License (CC BY). http://creativecommons.org/licenses/by/4.0/ cc) (i)

\section{Abstract}

This study evaluated whether the administration of a NSAID, sodium diclofenac, can promote alterations in the expression of Fos protein in central amygdala (CEA) and the lateral hypothalamus (LH) after $6 \mathrm{~h}$ of experimental tooth movement with a controlled force of $70 \mathrm{~g}$, applied to the superior central incisors of rats. Adult male rats were anesthetized and divided into four groups: Control, no orthodontic appliance $(\mathrm{OA}) ; \mathrm{OA}$ activated with $70 \mathrm{~g}$; $\mathrm{OA}$ activated with $70 \mathrm{~g}$ and pretreated with diclofenac sodium ( $5 \mathrm{mg} / \mathrm{kg}$, intramuscular); and diclofenac sodium alone. Six hours after the onset of the experiment the rats were reanesthetized and perfused with $4 \%$ paraformaldehyde. The brains were removed and fixed, and sections containing the CEA and LH were processed for Fos protein immunohistochemistry. The results show that in the control group, intramuscular injection of a ketamine/xylazine mixture did not induce IR-Fos cells in the CEA or LH. However, in the 70 g group, IR-Fos was the strongest observed $(P<0.05$, Newman-Keuls) in the CEA and LH compared with the other groups. Furthermore, pretreatment with sodium diclofenac reduced IR-Fos in these regions. Pretreatment with diclofenac sodium reduced Fos protein immunoreactivity in the CEA and LH induced by orthodontic force application. The expression of Fos protein in the CEA and LH is dependent, at least in part, on the inflammatory reaction induced by teeth movement. Diclofenac can be an alternative medication of choice for relief of orthodontic pain.

\footnotetext{
${ }^{*}$ Corresponding author.
} 


\section{Keywords}

\section{Amygdala, Lateral Hypothalamus, Fos Protein, Orthodontic Movement, Sodium Diclofenac}

\section{Introduction}

In clinical orthodontic treatment, tooth movement is widely used. Orthodontists have reported that patients often complain of discomfort and abnormal sensations, including pain sensation, following the application of orthodontic forces [1].

From the mid 1990s, studies have investigated the changes that occur in the central nervous system following tooth movement. Research shows that the Fos protein is a marker of neuronal activity and analysis of its expression has been used as an effective technique for this purpose. Fos protein is the product of c-Fos expression and can be detected using immunohistochemistry techniques. It is transiently expressed in neurons within an hour following stimulation and persists for at least a few hours [2]. Studies have shown that experimental tooth movement elicited Fos expression in the trigeminal subnucleus caudalis and in the lateral parabrachial nucleus 24 hours after the initiation of experimental tooth movement [3]. Moreover, the application of forces to achieve experimental tooth movement induced Fos protein immunoreactivity in the thalamic and hypothalamic nuclei 4 and in the central amygdale [4] [5]. These structures are involved in the transmission and modulation of nociceptive information [6].

Clinical observation shows that this discomfort and pain usually appear a few hours after the application of force [1]. Orthodontic forces cause an inflammatory event resulting in the local release of substances like prostaglandin and substance $\mathrm{P}$, which could be related to the mechanism of pain sensation [7]. Cyclooxygenase-2 (COX-2) is the dominant source of prostaglandins induced by inflammatory stimuli [8]. Marked increase in COX-2 expression was shown to occur not only locally at the site of inflammation, but also in neurons, glia and endothelial cells in the spinal cord and brain during inflammatory pain [9]. Nonsteroidal anti-inflammatory drugs (NSAIDs) inhibit the two isoforms of prostaglandin $\mathrm{H}$ synthase [cyclooxygenase (COX)], COX-1 and COX-2, the enzymes responsible for the formation of prostaglandins from arachidonic acid [8].

Regarding the use of NSAIDs for the treatment of orofacial pain, the effect of the administration of diclofenac sodium in the orofacial formalin test was evaluated. The results demonstrated that this drug produced dose-dependent inhibition of the nociceptive index in the acute and tonic phases of this test [10]. In addition, the use of NSAIDs is effective in the management of pain resulting from orthodontic treatment. Studies show that these drugs reduce the number of bone resorption lacunae areas of compression teeth receiving orthodontic force application compared with rats that did not receive anti-inflammatory agents [11].

This study evaluated the effects of treatment with diclofenac sodium, a potent NSAID, in the activation of central amygdala and lateral hypothalamus neurons following experimental tooth movement.

\section{Materials and Methods}

\subsection{Animals}

Twenty-seven male Wistar rats weighing 230 - $250 \mathrm{~g}$ were kept in Plexiglas wall cages in a room maintained at $24^{\circ} \mathrm{C}$, on a 12-hour light cycle (lights on at $7 \mathrm{am}$ ), with free access to water and food. The experiments were conducted according to and with the approval of the ethical recommendations of the Committee for Animal Care and Use of the University of São Paulo, Campus of Ribeirão Preto (Process 04.1.681.53.4). All efforts were made to minimize animal suffering.

\subsection{Experimental Procedure}

The experiments were performed between 8 a.m. and 12 p.m. Before the experiments, the rats were anesthetized by an intramuscular injection of ketamine $(100 \mathrm{mg} / \mathrm{kg})$ plus xylazine $(14 \mathrm{mg} / \mathrm{kg})$ and divided into four experimental groups: Control $(n=8)$, rats only submitted to the anesthetic procedure; OA $(n=8)$, rats that received an orthodontic appliance (OA) activated with 70g fixed on the maxillary incisors to induce tooth movement; DS + OA $(n=6)$, as per the OA group but pretreated with diclofenac sodium $(5 \mathrm{mg} / \mathrm{kg}$, intramuscular) $30 \mathrm{~min}$ before 
the induction of tooth movement; and DS w/o OA $(\mathrm{n}=5)$, rats injected with diclofenac sodium $(5 \mathrm{mg} / \mathrm{kg}$, intramuscular) alone.

\subsection{Orthodontic Appliance (OA)}

A fixed OA was constructed based on the model used by Magdalena et al. [12] consisting of a torsion spring made of 0.016 inches of stainless steel, with each edge welded to two stainless steel rings (orthodontic bands) of $0.004 \times 0.06$ inches that were cut open in the middle so that they could be fixed to the right and left incisors (Figure 1). This appliance was activated with a force of $70 \mathrm{~g}$ using a dynamometer and briefly heated so the wire would memorize the force applied. Next, the appliance was fitted with the torsion spring and adapted to the rat's palate in such a way that the orthodontic band could be cemented to the incisor with zinc oxyphosphate.

\subsection{Fos Protein Immunohistochemistry}

The rats were deeply anesthetized $6 \mathrm{~h}$ following the onset of the experimental procedure with an intramuscular injection of ketamine $(100 \mathrm{mg} / \mathrm{kg})$ plus xylazine $(14 \mathrm{mg} / \mathrm{kg})$ and transcardially perfused with $200 \mathrm{~mL}$ phosphate buffered saline (PBS, $0.01 \mathrm{M}$, pH 7.4) followed by $200 \mathrm{~mL}$ of $4 \%$ paraformaldehyde in $0.1 \mathrm{M}$ phosphate buffer $(\mathrm{pH} 7.4)$ at $4^{\circ} \mathrm{C}$. The brains were rapidly removed and soaked in the same fixative solution for $2 \mathrm{~h}$ at $4^{\circ} \mathrm{C}$ and then cryoprotected by overnight soaking in $30 \%$ sucrose/phosphate buffer, after which the brains were frozen in isopentane at $-40^{\circ} \mathrm{C}$. Subsequently, $40 \mu \mathrm{m}$ coronal sections were cut inside a cryostat and processed for Fos immunocytochemistry. Briefly, tissue sections were successively washed and incubated for $20 \mathrm{~h}$ with the primary Fos antibody (1:2000; SC 7202, Santa Cruz Biotechnology, Santa Cruz, CA, USA). The sections were then processed using the avidin biotin immunoperoxidase method (Vectastain ABC Kit; Vector Laboratories, Burlingame, CA, USA) and IR-Fos was revealed by the addition of the chromogen 3,3-diaminobenzidine (DAB; Sigma) and $1 \%$ hydrogen peroxide. The polyclonal anti-c-Fos antibody was omitted in negative controls. The slices were rinsed in PBS, mounted on gelatin-pretreated slides, dehydrated through an ethanol series, xylene-cleared, and cover-slipped for microscopic observations. For all experiments, tissues from the control and experimental rats were always processed in the same assay. The brain regions analyzed in this study were the central amygdala (CEA) and lateral hypothalamus (LH).

\subsection{Quantitative Analysis}

The sections were analyzed using light microscopy and labeled neurons were recorded using an image analysis system (Zeiss KS 300). The anatomic description of brain regions followed the Paxinos and Watson atlas [13]. For a cell to be considered to express IR-Fos, the nucleus of the neuron had to be of an appropriate size (cell neuron diameter ranging from approximately 8 to $15 \mu \mathrm{m}$ ) and shape (oval or round) and be distinct from the background at $10 \times$ magnification. For quantitative analysis of Fos-labeled cells, three consecutive sections of

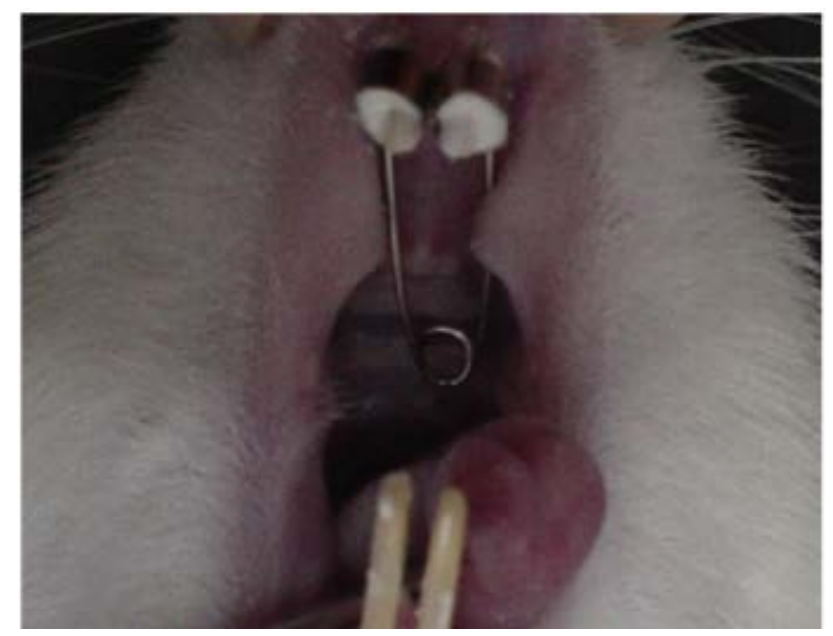

Figure 1. View of the activated appliance set on the rat maxilla. 
the brain region of interest were taken from each rat. In each section, the number of Fos-positive neurons was counted unilaterally in the study area by one observer blinded to treatment using a light microscope with a $10 \times$ objective and the absence or presence of labeled neurons was registered using an image analysis system (Image $\mathrm{J})$. The data are presented as mean \pm standard error of the mean and were analyzed by one-way analysis of variance (ANOVA) followed by the Newman-Keuls test. The level of significance was set as $\mathrm{P}<0.05$.

\subsection{Drugs}

Diclofenac sodium (Diclofenaco 50-Ouro Fino Saúde Animal Ltda.) was used at a dilution of 5\% in 0.9\% saline vehicle. The dose used was $5 \mathrm{mg} / \mathrm{kg}$, intramuscularly (IM). This dose was based on previous studies by Retamoso et al. [14].

\section{Results}

To evaluate the effect of the anesthesia, the number of protein immunoreactive (IR-Fos) cells was analyzed in the area studied in control rats, i.e. rats that were only submitted to the intramuscular injection of ketamine/xylazine mixture. In this group, reduced expression of Fos protein was observed with only a few dispersed IR-Fos cells located in the CEA and LH (Figure 2).

In rats fitted with an OA with a controlled force of $70 \mathrm{~g}$, an increase in the density of IR-Fos cells was observed $6 \mathrm{~h}$ after the application of this force (Figure 2). Pretreatment with the NSAID diclofenac sodium (DS + $\mathrm{OA}), 30$ min prior to orthodontic movement, produced a significant reduction in the number of IR-Fos cells in the CEA and LH $6 \mathrm{~h}$ after activation. In rats administered the NSAID but not submitted to tooth movement (DS w/o OA), the mean number of IR-Fos cells in the CEA and in the LH were similar to Control group (Figure 2). Statistical analysis demonstrated a significant difference between treatments for these nuclei (F3, 26 = 33.95; F3, $26=33.47, \mathrm{P}<0.001$ ANOVA for CEA and LH, respectively). The Newman-Keuls post-hoc test showed that mean number of IR-Fos cells in the groups treated with an OA activated with 70g were different compared with the remaining groups (Control, DS + OA and DS w/o OA) in the both nuclei studied $(\mathrm{P}<0.05)$. Furthermore, the number of IR-Fos cells in the DS + OA groups was different compared with Control, OA and DS w/o OA (P $<0.05$, Newman-Keuls, Figure 2).

\section{Discussion}

The results obtained here showed that preadministration of sodium diclofenac, a potent NSAID, promoted a re-

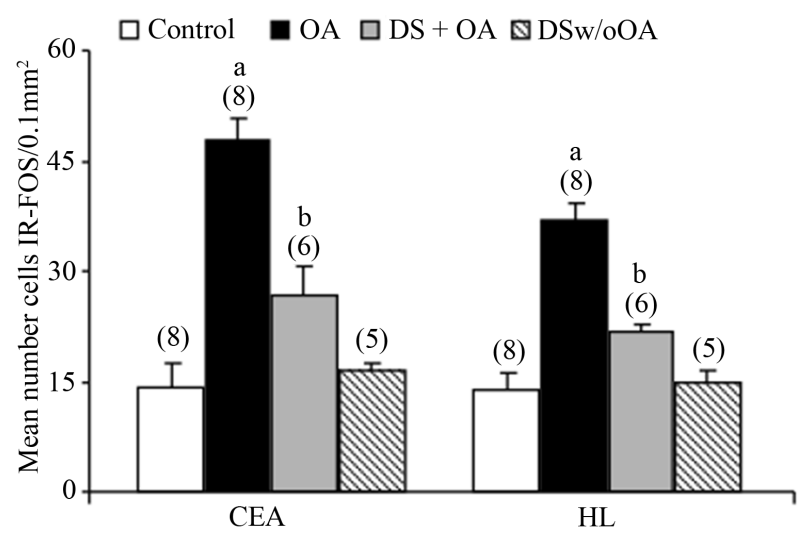

Figure 2. Mean number cells IR-Fos (mean \pm standard error of the mean) in the central amygdala (CEA) and lateral hypothalamus ( $\mathrm{LH})$ in the group with no orthodontic appliance (Control), in the OA activated group (OA), in the OA activated group pretreated with diclofenac sodium (DS + OA) and in the group treated with diclofenac sodium without OA (DS w/o OA). a and b $\mathrm{P}<0.05$ compared with the remaining groups by the Newman-Keuls test. Number of rats analyzed in parentheses. 
duction in the IR-Fos cells, suggesting, at least in part, that the activation of cells in structures related to the affective-motivational component of pain is due to inflammation resulting from the application of orthodontic force. Additionally, the results corroborated a prior report that demonstrated an increase in the density of immunoreactive Fos protein cells in the CEA and LH, after the rats had been submitted to controlled movement with a force of $70 \mathrm{~g}$ to achieve distalization of the maxillary central incisors [5].

It is known that the CEA is implicated in the production of affective responses and contributes to noxious processing [15]. Neural activity in the CEA is increased by acute nociceptive stimulation or chronic pain in rats [15] [16]. Moreover, neuroimaging studies have shown the involvement of the amygdala in processing the affective component of pain in humans [17] [18]. The hypothalamus and thalamus also appear to be targets for certain direct nociceptive inputs from the spinal and medullary dorsal horn [19] [20]. Fos expression was observed in the paraventricular nucleus of the hypothalamus and the paraventricular nucleus of the thalamus following other forms of noxious stimulation, such as formalin injection into the rat footpad [21].

Studies also show that the tooth movement induced significant expression of Fos protein in the central nucleus of the amygdala, the paraventricular nucleus of the hypothalamus and the paraventricular nucleus of the thalamus [4]. In agreement with these data, our results corroborated a pioneer report that showed an increased in Fos protein in the central nucleus of the amygdala and lateral nucleus of the hypothalamus induced by tooth movement [5].

The use of orthodontic appliances has also resulted in neuronal activation in other brain structures. A substantial number of IR-Fos neurons have been observed in the spinal trigeminal caudalis, parabrachial nucleus, periaqueductal gray matter and dorsal raphe. Neuronal activation also occurs to a lesser extent in the trigeminal interpolaris and locus coeruleus [12].

One possible explanation is that the presence of IR-Fos cells in the CEA and LH is due to transmission of nociceptive inflammatory information through spino (trigemino) parabrachiohypothalamic [20], the spinohypothalamic [19] and the spino (trigemino) pontoamygdaloid pathways [6]. These pathways project to the side of the parabrachial area, which retransmits this nociceptive information to the amygdala and hypothalamus. Another possible explanation is that the nociceptive stimuli activate monoaminergic descending pathways of nociceptive control [22]. Tooth movement is capable of promoting increased release of serotonin in the bulbar regions and periaqueductal gray [23]. Madaglena et al. [12] has shown that tooth movement induced Fos protein staining in the dorsal raphe, a region that produces intense serotonergic innervation to the amygdala and hypothalamus.

It has been suggested that pain due to tooth movement is caused by events such as periodontal ligament and bone tissue pressure, edema and ischemia, which results in the release of inflammatory mediators [24] [25]. In this context, studies have shown the role of COX-2 as a regulator of the transmission of nociceptive information [9] [26]. COX-2 was shown to be increased in the caudal trigeminal nucleus and was involved in orofacial pain resulting from experimental tooth movement [27].

NSAIDs are frequently used as analgesics in dental clinical practice, because of the ability to inhibit the activity of the cyclooxygenase enzymes that transform arachidonic acid to prostaglandins 28. Furthermore, due prostaglandins are important mediators of bone resorption [28] [29], these medications can affects the rate of orthodontic tooth movement [30]. In this way, acetaminophen, that is a NSAID belonging to the family of paraminophenols, which by not inhibiting PGs or by inhibiting them slightly, is the drug of choice for treating the discomfort of tooth movement [28] [29] [31]. Moreover, although higher dose (10 mg/kg) of diclofenac (a subgroup of NSAID) administrated in the gingiva, also has alter the orthodontic tooth movement [29], daily systemic dose of $5 \mathrm{mg} / \mathrm{kg}$ diclofenac for fourteenth days did not modified the bone neoformation on the tension side of the tooth movement in rats [14].

Previous studies have shown a decrease in Fos protein in brain structures related to pain, following the administration of NSAIDs [32] [33]. In the present study, preadministration of diclofenac sodium, promoted a reduction in the IR-Fos cells in CEA and LH, suggesting, at least in part, that the activation of cells in these structures related to the affective-motivational component of pain is due to inflammation resulting from the application of orthodontic force. So, it is possible to suggest that diclofenac can be useful to management of orthodontic pain.

\section{Conclusion}

- Pretreatment with diclofenac sodium reduced Fos protein immunoreactivity in the CEA and LH induced by orthodontic force application. 
- The expression of Fos protein in the CEA and LH is dependent, at least in part, on the inflammatory reaction induced by teeth movement.

- Diclofenac can be an alternative medication of choice for relief of orthodontic pain.

\section{Acknowledgements}

The authors would like to thank Patrícia Adriana Basile for her technical assistance. This work was supported by CAPES/PROEX and FAPESP. A. C. Desiderá is the recipient of a Master's degree scholarship from FAPESP (\# 2010/14316). G. C. Nascimento has a Doctor degree scholarship from FAPESP (Grant no. 2011/07718-9). C.R.A. Leite-Panissi receives research grants from the CNPq (Grant no. 307383/2012 to C.R.A.L.P.).

\section{References}

[1] Ngan, P., Kess, B. and Wilson, S. (1989) Perception of Discomfort by Patients Undergoing Orthodontic Treatment. American Journal of Orthodontists and Dentofacial Orthopedics, 96, 47-53. http://dx.doi.org/10.1016/0889-5406(89)90228-X

[2] Aihara, Y., Maeda, T., Hanada, K. and Wakisaka, S. (1999) Effects of Morphine on the Distribution of Fos Protein in the Trigeminal Subnucleus Caudalis Neurons during Experimental Tooth Movement of the Rat Molar. Brain Research, 819, 48-57. http://dx.doi.org/10.1016/S0006-8993(98)01323-7

[3] Yamashiro, T., Nakagawa, K., Satoh, K., Moriyama, H. and Takada, K. (1997) C-Fos Expression in the Trigeminal Sensory Complex and Pontine Parabrachial Areas Following Experimental Tooth Movement. Neuroreport, 8, 2351-2353. http://dx.doi.org/10.1097/00001756-199707070-00049

[4] Yamashiro, T., Satoh, K., Nakagawa, K., Moriyama, H., Yagi, T. and Takada, K. (1998) Expression of Fos in the Rat Forebrain Following Experimental Tooth Movement. Journal of Dental Research, 77, 1920-1925. http://dx.doi.org/10.1177/00220345980770110901

[5] Novaes, A.P.N., Rocha, M.J.A. and Leite-Panissi, C.R.A. (2010) Tooth Movement Activates the Central Amygdala and the Lateral Hypothalamus by the Magnitude of the Force Applied. Angle Orthodontist, 80, 111-115. http://dx.doi.org/10.2319/100708-522.1

[6] Bernard, J.F., Peschanski, M. and Besson, J.M. (1989) A Possible Spino (Trigemino)-Ponto-Amygdaloid Pathway for Pain. Neuroscience Letters, 100, 83-88. http://dx.doi.org/10.1016/0304-3940(89)90664-2

[7] Ferreira, S.H., Nakamura, M. and de Abreu Castro, M.S. (1978) The Hyperalgesic Effects of Prostacyclin and Prostaglandin E2. Prostaglandins, 16, 31-37. http://dx.doi.org/10.1016/0090-6980(78)90199-5

[8] McAdam, B.F., Mardini, I.A., Habib, A., Burke, A., Lawson, J.A., Kapoor, S., et al. (2000) Effect of Regulated Expression of Human Cyclooxygenase Isoforms on Eicosanoid and Isoeicosanoid Production in Inflammation. Journal of Clinical Investigation, 105, 1473-1482. http://dx.doi.org/10.1172/JCI9523

[9] Samad, T.A., Moore, K.A., Sapirstein, A., Billet, S., Allchorne, A., Poole, S., et al. (2001) Interleukin-1beta-Mediated Induction of Cox-2 in the CNS Contributes to Inflammatory Pain Hypersensitivity. Nature, 410, 471-475. http://dx.doi.org/10.1038/35068566

[10] Sukriti, Hota, D. and Pandhi, P. (2004) Potentiation of Antihyperalgesic Activity of Diclofenac by Nimodipine in a Formalin Model of Facial Pain in Rats. Methods \& Findings in Experimental \& Clinical Pharmacology, 26, 253-256.

[11] Arias, O.R. and Marquez-Orozco, M.C. (2006) Aspirin, Acetaminophen, and Ibuprofen: Their Effects on Orthodontic Tooth Movement. American Journal of Orthodontists and Dentofacial Orthopedics, 130, 364-370. http://dx.doi.org/10.1016/j.ajodo.2004.12.027

[12] Magdalena, C.M., Navarro, V.P., Park, D.M., Stuani, M.B. and Rocha, M.J. (2004) c-Fos Expression in Rat Brain Nuclei Following Incisor Tooth Movement. Journal of Dental Research, 83, 50-54. http://dx.doi.org/10.1177/154405910408300110

[13] Paxinos, G. and Watson, C. (2007) The Rat Brain in Stereotaxic Coordinates. 6th Edition, Academic Press, San Diego.

[14] Retamoso, L., Knop, L., Shintcovsk, R., Maciel, J.V., Machado, M.A. and Tanaka, O. (2011) Influence of Anti-Inflammatory Administration in Collagen Maturation Process during Orthodontic Tooth Movement. Microscopy Research and Technique, 74, 709-713. http://dx.doi.org/10.1002/jemt.20947

[15] Bernard, J.F., Huang, G.F. and Besson, J.M. (1992) Nucleus Centralis of the Amygdala and the Globus Pallidus Ventralis: Electrophysiological Evidence for an Involvement in Pain Processes. Journal of Neurophysiology, 68, 551-569.

[16] Li, W. and Neugebauer, V. (2004) Block of NMDA and Non-NMDA Receptor Activation Results in Reduced Background and Evoked Activity of Central Amygdala Neurons in a Model of Arthritic Pain. Pain, 110, 112-122. http://dx.doi.org/10.1016/i.pain.2004.03.015 
[17] Kulkarni, B., Bentley, D.E., Elliott, R., Youell, P., Watson, A., Derbyshire, S.W., Frackowiak, R.S.J., Friston, K.J. and Jones, A.K.P. (2005) Attention to Pain Localization and Unpleasantness Discriminates the Functions of the Medial and Lateral Pain Systems. European Journal of Neuroscience, 21, 3133-3142. http://dx.doi.org/10.1111/j.1460-9568.2005.04098.x

[18] Schneider, F., Habel, U., Holthusen, H., Kessler, C., Posse, S., Muller-Gartner, H.W. and Arndt, J.O. (2001) Subjective Ratings of Pain Correlate with Subcortical-Limbic Blood Flow: An fMRI Study. Neuropsychobiology, 43, 175-185. http://dx.doi.org/10.1159/000054887

[19] Giesler, G.J. (1995) The Spino-Hypothalamic Tract. In: Besson, J.M., Guildbaud, G. and Ollat, H., Eds., Forebrain Areas Involved in Pain Processing, Eurotext, Paris, 13-25.

[20] Bester, H., Menendez, L., Besson, J.M. and Bernard, J.F. (1995) Spino (Trigemimo) Parabrachiohypothalamic Pathway: Electrophysiological Evidence for an Involvement in Pain Processes. Journal of Neurophysiology, 73, 568-585.

[21] Senba, E., Matsunaga, K., Tohyamat, M. and Noguchi, K. (1993) Stress-Induced c-Fos Expression in the Rat Brain: Activation Mechanism of Sympathetic Pathway. Brain Research Bulletin, 31, 329-344. http://dx.doi.org/10.1016/0361-9230(93)90225-Z

[22] Basbaum, A.I. and Fields, H.L. (1984) Endogenous Pain Control Systems: Brainstem Spinal Pathways and Endorphin Circuitry. Annual Review of Neuroscience, 7, 309-338. http://dx.doi.org/10.1146/annurev.neuro.7.1.309

[23] Yamashiro, T., Fukunaga, T., Kabuto, H., Ogawa, N. and Takano-Yamamoto, T. (2001) Activation of the Bulbospinal Serotonergic System during Experimental Tooth Movement in the Rat. Journal of Dental Ressearch, 80, 1854-1857. http://dx.doi.org/10.1177/00220345010800091601

[24] Giannopoulou, C., Dudic, A. and Kiliaridis, S. (2006) Pain Discomfort and Crevicular Fluid Changes Induced by Orthodontic Elastic Separators in Children. Journal of Pain, 7, 367-376. http://dx.doi.org/10.1016/j.jpain.2005.12.008

[25] Kato, J., Wakisaka, S. and Kurisu, K. (1996) Immunohistochemical Changes in the Distribution of Nerve Fibers in the Periodontal Ligament during an Experimental Tooth Movement of the Rat Molar. Cells Tissues Organs, 157, 53-62. http://dx.doi.org/10.1159/000147866

[26] Vardeh, D., Wang, D., Costigan, M., Lazarus, M., Saper, C.B., Woolf, C.J., FitzGerald, G.A. and Samad, T.A. (2009) $\mathrm{COX}_{2}$ in CNS Neural Cells Mediates Mechanical Inflammatory Pain Hypersensitivity in Mice. Journal of Clinical Investigation, 119, 287-294. http://dx.doi.org/10.1172/JCI37098

[27] Gao, Y. and Duan, Y.Z. (2010) Increased $\mathrm{COX}_{2}$ in the Trigeminal Nucleus Caudalis Is Involved in Orofacial Pain Induced by Experimental Tooth Movement. The Anatomical Record, 293, 485-491. http://dx.doi.org/10.1002/ar.21078

[28] Karthi, M., Anbuslevan, G.J., Senthilkumar, K.P., Tamizharsi, S., Raja, S. and Prabhakar, K. (2012) NSAIDs in Orthodontic Tooth Movement. Journal of Pharmacy and BioAllied Sciences, 4, S304-S306. http://dx.doi.org/10.4103/0975-7406.100280

[29] De Carlos, F., Cobo, J., Díaz-Esnal, B., Arguelles, J., Vijande, M. and Costales, M. (2006) Orthodontic Tooth Movement after Inhibition of Cyclooxygenase-2. American Journal of Orthodontics and Dentofacial Orthopedics, 129, $402-$ 406. http://dx.doi.org/10.1016/j.ajodo.2005.11.020

[30] Krishnan, V. and Davidovitch, Z. (2006) The Effect of Drugs on Orthodontic Tooth Movement. Orthodontic \& Craniofacial Research, 9, 163-171. http://dx.doi.org/10.1111/j.1601-6343.2006.00372.x

[31] Shetty, N., Patil, A.K., Ganeshkar, S.V. and Hegde, S. (2013) Comparison of the Effects of Ibuprofen and Acetaminophen on PGE $_{2}$ Levels in the GCF during Orthodontic Tooth Movement: A Human Study. Progress in Orthodontics, 14, 6. http://dx.doi.org/10.1186/2196-1042-14-6

[32] Orita, S., Ishikawa, T., Miyagi, M., Ochiai, N., Inoue, G., Eguchi, Y., et al. (2012) Percutaneously Absorbed NSAIDs Attenuate Local Production of Proinflammatory Cytokines and Suppress the Expression of c-Fos in the Spinal Cord of a Rodent Model of Knee Osteoarthritis. Journal of Orthopaedic Science, 17, 77-86. http://dx.doi.org/10.1007/s00776-011-0175-7

[33] Stabile, A.C., Stuani, M.B.S., Leite-Panissi, C.R.A. and Rocha, M.J.A. (2009) Effects of Short-Term Acetaminophen and Celecoxib Treatment on Orthodontic Tooth Movement and Neuronal Activation in Rat. Brain Research Bulletin, 79, 396-401. http://dx.doi.org/10.1016/j.brainresbull.2009.05.014 